\title{
Demonstrating Fuel Flexibility in Commercial Operation*
}

\author{
Fawad Khan", Francis Lau \\ Synthesis Energy Systems Inc., Houston, USA \\ Email: $\left\{{ }^{\#}\right.$ fawad.khan, francis.lau\}@synthesisenergy.com
}

Received February 15, 2012; revised March 16, 2012; accepted April 7, 2012

\begin{abstract}
Synthesis Energy Systems Inc. (SES) enables its customers to advance gasification projects through commercial scale feedstock testing at its commercial scale coal to syngas facility in Zhao Zhuang City (ZZ Plant), Shandong Province, China. These tests help customers affirm individual project economic viability and reduce technology risk. Included in these test campaigns have been one and two-week long continuous operations at varying loads and on widely-varying feedstock such as Chinese Inner Mongolian lignite, Chinese sub-bituminous high ash (and high friable) coal, and Australian Queensland high ash sub-bituminous coal. Through these campaigns, SES has progressed one project into the detailed engineering and construction phase and one project into the feasibility study phase. SES believes that the ability to perform these commercial scale campaigns without interruption of operation is unique to SES. The ZZ Plant, which sells clean syngas to a neighboring methanol facility, has been in operation since early 2008 on a design coal of high ash middlings (washery wastes) from ROM bituminous coal (30\% - 40\% wt ash). SES has made significant improvements to the design, operation, and efficiency of the ZZ Plant and U-GAS technology that is licensed from Gas Technology Institute (GTI). Included in these is the Fines Management System (FMS), which has demonstrated overall carbon conversion of greater than $98 \%$. The ZZ Plant consistently demonstrates fuel flexibility and greater than $98 \%$ availability, $98 \%$ carbon conversion, and $80 \%$ cold gas efficiency.
\end{abstract}

Keywords: Gasification; U-GAS; Fluid Bed Gasification; Low Rank Coal; Lignite, Biomass

\section{Introduction}

SES is a global energy and gasification technology company that provides products and solutions to the energy and chemicals industries. SES operates in regions where low-rank coal and biomass feedstocks can be profitably converted into high-value products through the application of SES' gasification technology. SES unlocks the value of these low-cost resources by providing a proprietary technology package whereby SES licenses its technology rights to third parties, delivers an engineered technology transfer package, and provides proprietary equipment components to customers who plan to own and operate projects. In addition, SES may partner with engineering, equipment and technology companies to provide its gasification technology package with an integrated modular product offering; invest in U-GAS (registered trademark of Gas Technology Institute) based projects either directly or through an investment partner; or acquire or partner with owners of low quality coal

\footnotetext{
*The original manuscript of this paper was initially included in the Proceedings of 28th Annual International Pittsburgh Coal Conference, September 12-15, 2011, Pittsburgh, PA.

"Corresponding author.
}

resources to create more value and opportunity for SES through the integration of its technology with the coal resources.

SES' proven gasification technology originated in the United States at the Gas Technology Institute (GTI) over 35 years ago. Since 1975, 11 pilot, demonstration, and commercial units have been designed and constructed. SES has demonstrated organizational technology development and operational skills that have led to an increase in retained proprietary know-how, trade secrets and technology capability. Furthermore, SES has a demonstrated track record of successfully implementing U-GAS with its first build-own-operate (BOO) project having over three years of successful operations and its second project on schedule.

\section{SES' Gasification Process}

SES' gasification process, based on U-GAS, is a singlestage,, fluidized-bed (bubbling-bed) technology for the production of low-to-medium heating value syngas from a wide array of coal and biomass feedstocks using oxygen, oxygen enriched air, or air in the gasification reac- 
tion. Within the bubbling bed, the feedstock reacts with steam and oxygen (either pure oxygen or oxygen in air). The reaction temperature is controlled to maintain high carbon conversion and non-slagging conditions for the ash. Carbon conversion and cold gas efficiencies of over $98 \%$ and $80 \%$, respectively, have been repeatedly demonstrated at commercial scale on a wide range of feedstocks including low quality coals and lignite. Figure 1 is a typical block flow diagram of SES' gasification process base configuration.

The gasifier feed system consists of weigh bins, conveyors, transporters and lockhopper systems that supply the gasifier with coal or biomass at pressure. The feedstock is pressurized in a lockhopper system and metered in to the gasifier. Carbon dioxide or nitrogen is typically used as the feedstock transport gas medium into the gasifier reactor. The gasification agents (steam and oxygen) enter the gasifier through the grid, annulus and the center jet at the bottom of the gasifier as illustrated in Figure 2 .

The gasification system consists of the gasifier, fines removal, ash discharge, and ash cooling systems. Within the fluidized bed, the feedstock reacts with steam and oxygen (either pure oxygen or oxygen in air). The process accomplishes four important functions in a singlestage bubbling-bed gasifier: it decakes, devolatilizes, and gasifies the feedstock, and if necessary, agglomerates and separates ash from the reacting coal. At the specified operating conditions, coal is gasified to produce a synthesis gas ("syngas") product consisting of hydrogen, carbon monoxide, carbon dioxide, water vapor, and methane, in addition to small amounts of ammonia, hydrogen sulfide, and other trace impurities.

The bottom ash flow rate through the ash discharge port is adjusted to obtain adequate ash discharge from the gasifier. The temperature and pressure of the coarse ash from the gasifier is reduced as ash flows through the ash

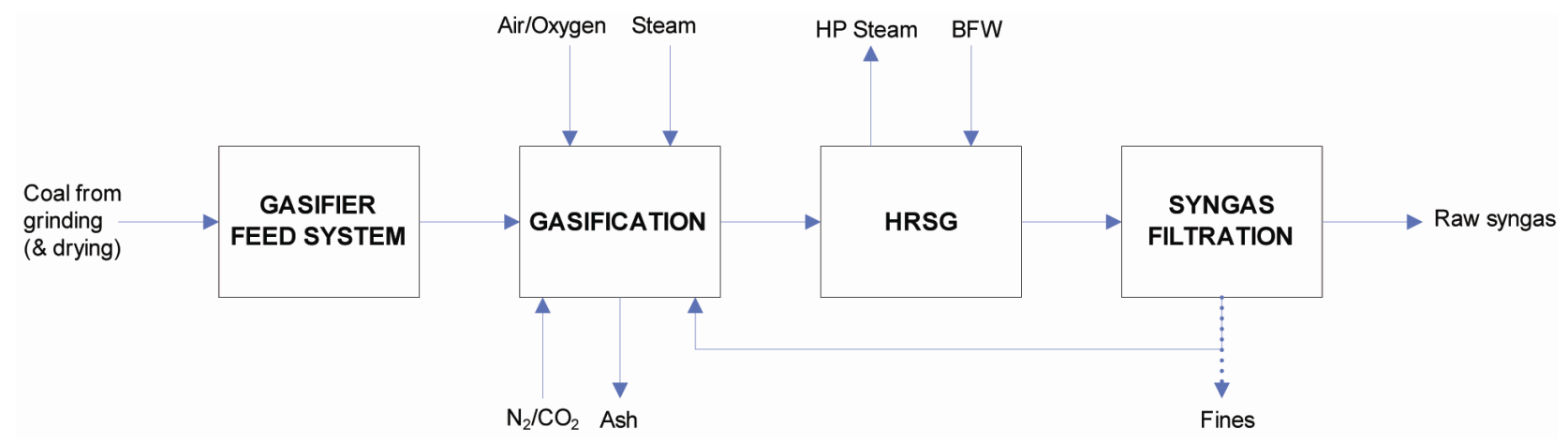

Figure 1. Typical SES' gasification process configuration.

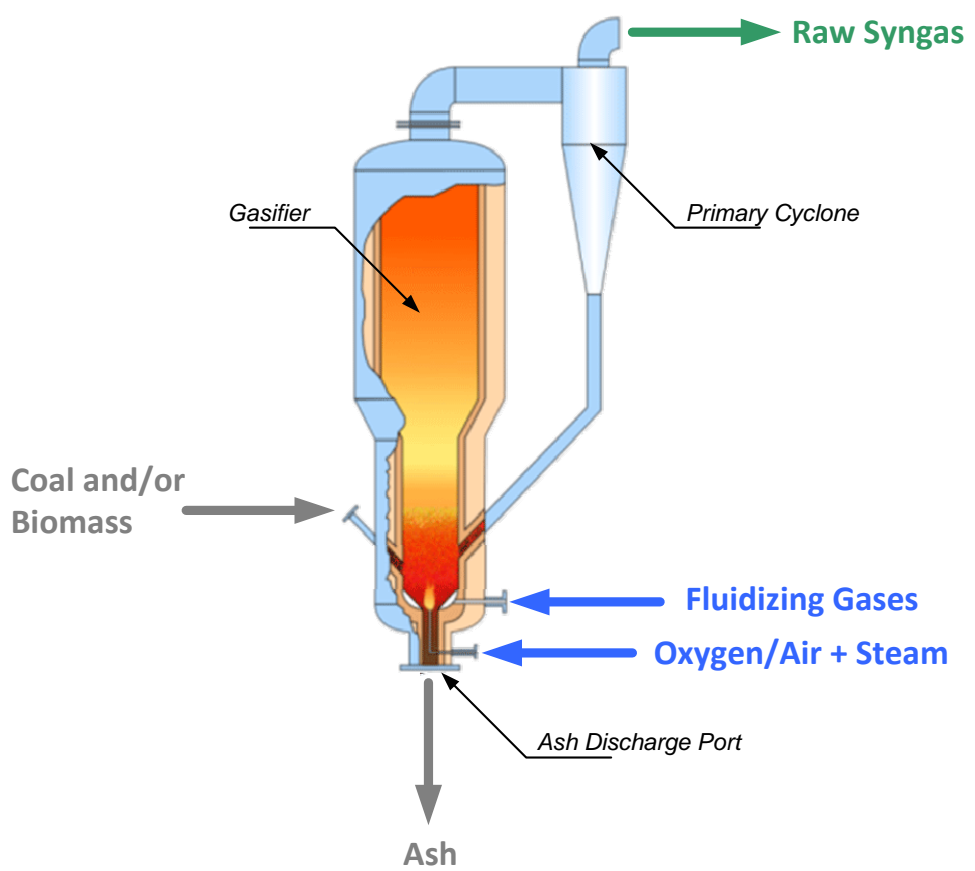

Figure 2. Gasifier configuration. 
classifier and bottom ash handling system. The bottom ash, upon leaving the ash classifier is, cooled and removed from the plant via an ash cooler, lockhopper system, and screw coolers before being transported outside by belt conveyors for truck unloading.

The primary fines recovery and recycle system consists of two cyclones in series, designated as the primary and secondary cyclones, which recover nearly all fines from the syngas stream leaving the gasifier. The primary cyclone is designed to efficiently recover entrained fines from the syngas with a relatively small pressure drop. The fines collected in the primary and secondary cyclones are returned to the gasifier by means of a dip-leg.

A heat recovery steam generator (HRSG) serves to increase the energy efficiency of the gasification system. Steam generated from the HRSG that is not used by the gasification process is exported to meet other plant needs including power generation. Cooled syngas leaving the HRSG then enters the downstream high-efficiency cyclone and filter system.

The collected fines from the high-efficiency cyclone and filter system are routed to a fines silo through a lockhopper system, where they are collected in the baghouse and returned to the gasifier for further conversion. This system is the Fines Management System (FMS), recently incorporated into SES' U-GAS design for maximizing carbon conversion, and has been proven at commercial scale.

\section{Major Process Improvement-SES’ Fines Management System}

Prior to 2010, the best-in-class carbon conversion for fluid bed gasification technologies was $97 \%$ [1]. In October 2010, SES implemented and successfully demonstrated its FMS at the ZZ Plant. Through its FMS, SES has been able to successfully recycle and gasify waste fines generated from the gasification process. The result has enabled SES' gasification process to achieve high carbon conversions (greater than 98\%) and cold gas efficiencies (greater than $80 \%$ ) on low quality feedstocks that may not be feasible to gasify in commercial slagging gasifiers. Furthermore, the FMS eliminates many challenges associated with fines (i.e. fly ash) disposal.

Figure 3 illustrates simulated gasifier performance on sub-bituminous coal for SES' gasification process with and without the FMS. Simulated gasfier performances on Illinois \#6 coal from slagging dry and slurry fed entrained and fixed bed gasification processes have been provided as a reference.

The carbon conversion and cold gas efficiency in Figure 3 are calculated values. The Slagging wet and dry feed gasification calculations are based on Department of Energy's IGGC performance study [2]. The Fixed bed gasification calculations are based on Department of En-

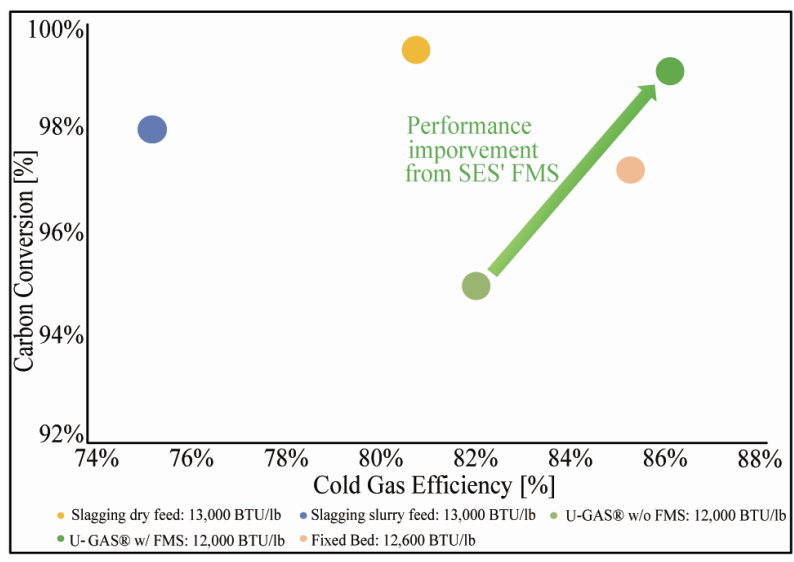

Figure 3. Comparative assessment of SES FMS system².

ergy's SNG performance study [3]. The Cold Gas Efficiency is defined as follows:

$$
=\frac{\text { Effective Syngas Output }\left(\mathrm{H}_{2}+\mathrm{CO}+\mathrm{CH}_{4}\right)\left[\frac{\mathrm{mmbtu}}{\mathrm{hr}}\right]}{\text { Coal Input }\left[\frac{\mathrm{mmbtu}}{\mathrm{hr}}\right]}
$$

\section{ZZ Commercial Operations}

In January 2008, SES completed construction of its ZZ Plant in Zao Zhuang City, China. The ZZ Plant is a 96\% SES owned joint venture with Shandong Hai Hua Coal \& Chemical Company Ltd. ("Hai Hua”). The ZZ plant consists of two gasification trains designed to process 400 metric tons per day of coal middlings with up to $40 \mathrm{wt}-\%$ ash. Clean syngas is sold over the fence to the JV partner, Hai Hua, for methanol production. During the first year of commercial operations, the plant achieved over 98\% availability of single gasifier capacity using low-value high-ash coal and coal washings. Moreover, the ZZ plant has achieved less than $1 \mathrm{~kg}$ of coal per normal cubic meter (NCM) of clean syngas (primarily carbon monoxide, hydrogen, and methane) and less than 0.4 NCM of oxygen per NCM of clean syngas. Figure 4 is a process block flow diagram representation of the ZZ Plant configuration.

The ZZ Plant continuously operates at $90 \%$ carbon dioxide $\left(\mathrm{CO}_{2}\right)$ capture from syngas through pressure swing absorption. Part of this $\mathrm{CO}_{2}$ is recycled back to the gasifier and the balance is directed to the flare.

\section{Fuel Flexibility}

A key advantage of SES' gasification technology is fuel flexibility. Typically, fluid bed gasification technologies require coal with high ash fusion temperatures $\left(>1830^{\circ} \mathrm{F}\right)$ to avoid ash agglomeration [4]. However, the U-GAS 


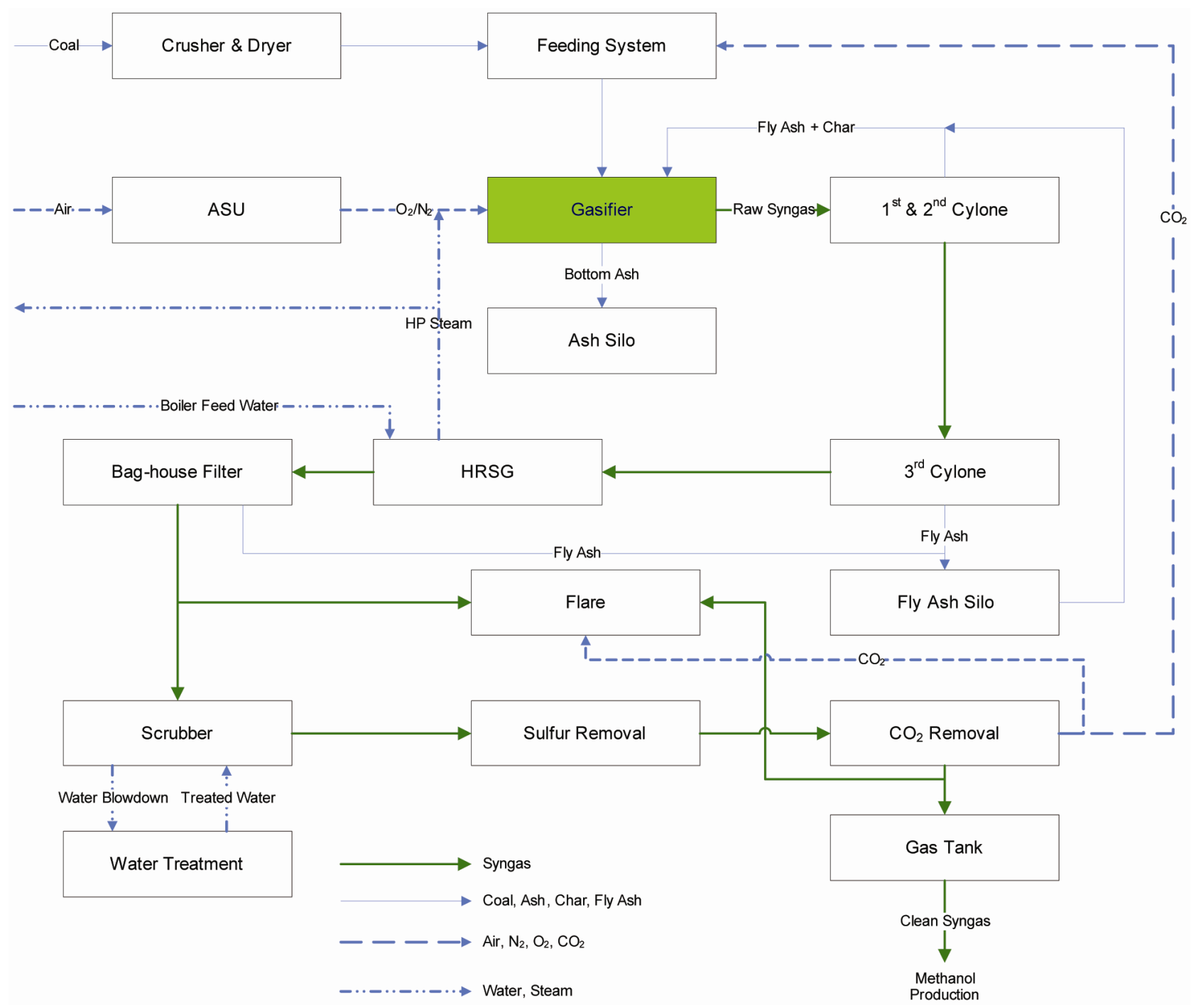

Figure 3. Zao Zhuang Plant block flow diagram.

process has features in its design that allow the technology to manage coals with ash that may agglomerate. The technology has been proven on many ranks of coal (low rank, high moisture, and high ash coals including Indian coal), coal waste products, and biomass feedstocks. Table 1 and Table 2 represents SES' bench, pilot and commercial scale feedstock test experience to date. This information should not be interpreted as technical limitations to SES' gasification process. SES evaluates commercial and technical viability of feedstocks on a case by case basis. At the ZZ Plant, SES continues to prove feedstock flexibility by on-stream switching of feedstocks without interrupting syngas supply to Hai Hua for its methanol production.

In 2004 and 2005, Nexant conducted a successful evaluation of the U-GAS technology for USDAID/India in association with the National Thermal Power Company of India and USDOE/NETL. The evaluation included testing of Indian coal with 34 - 41 wt\% ash from the North Karanpura coal fields. The ROM and washed Indian coals were successfully gasified under air-blown operating conditions in GTI's pilot scale U-GAS reactor at feed rates up 11 ston/day and pressures up to 304 psi(g) [5].

Since the commercial operation of its ZZ Plant in 2008, SES has successfully conducted test campaigns for third parties on off-design coals including high ash sub-bituminous coal, Inner Mongolian Lignite and high ash Australian brown coal. Operating flexibility is critical to a project's success where there is uncertainty in fuel availability and pricing. Figure 5 below provides a simplified operating envelope (fuel preference) when presented with a high moisture sub-bituminous and high ash coal.

The colors illustrate the pay-off opportunity by operating on the respective coal at the specified price combination. Traditional net present value approaches fail to 
Table 1. Gasification feedstock experience.

\begin{tabular}{|c|c|}
\hline Coalk & Coal Source \\
\hline Bituminous Coals & $\begin{array}{l}\text { - } \text { Western Kentucky No. 9, washed \& } \\
\text { - } \quad \text { Wun-of-Mine (ROM) } \\
\text { - } \quad \text { Illinois No. 6, Peabody No. } 10 \text { and } \\
\text { - } \quad \text { Pittsburgh No. 8, Champion and Ireland } \\
\text { - } \quad \text { Australian, Bayswater No. 2, Sydney } \\
\text { - } \quad \text { Polish, Silesia } \\
\text { - } \quad \text { French, Merlebach-ROM } \\
\text { - Utah - ROM } \\
\text { - Colombian } \\
\text { - Indian, North Karanpura, washed and } \\
\text { - } \quad \text { SOMandong-High ash, ROM, and coal } \\
\text { washing middlings }\end{array}$ \\
\hline $\begin{array}{c}\text { Sub-Bituminous and } \\
\text { Lignite }\end{array}$ & $\begin{array}{ll}\text { - } & \text { Chinese, Shen Fu Sub-Bituminous } \\
\text { - } & \text { Henan Yima Sub-Bituminous } \\
\text { - } & \text { Montana Rosebud, Colstrip } \\
\text { - } & \text { Wyoming, Big Horn } \\
\text { - } & \text { North Dakota lignite, Freedom } \\
\text { - } & \text { Saskatchewan lignite } \\
\text { - } & \text { Inner Mongolia lignite }\end{array}$ \\
\hline $\begin{array}{c}\text { Coke, Char, Peat, \& } \\
\text { Waste }\end{array}$ & 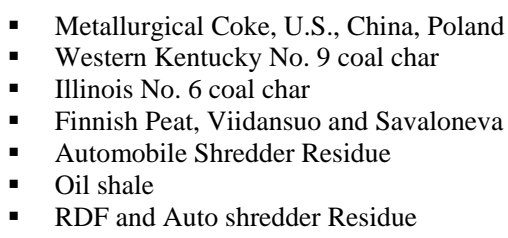 \\
\hline Biomass & $\begin{array}{l}\text { - Finnish waste wood and pulp mill waste } \\
\text { - Danish Willow } \\
\text { - } \text { Danish Straw } \\
\text { - Pelletized alfalfa stems } \\
\text { - Pelletized waste wood } \\
\text { - } \text { Bagasse } \\
\text { - } \text { Rice straw } \\
\text { - } \text { Chicken litter }\end{array}$ \\
\hline
\end{tabular}

Table 2. Tested feedstock property ranges.

\begin{tabular}{cc}
\hline Feedstock Property & Tested Range \\
\hline Moisture Content, wt\% & $1-41$ \\
Volatile Matter, wt\% & $3-69$ \\
Fixed Carbon, wt\% & $6-83$ \\
Sulfur, wt $\%$ & $0.2-4.6$ \\
Free Swelling Index & $0-8$ \\
Ash Content, wt $\%$ & $<1 \%-55 \%$ \\
Ash Softening- ${ }_{1},{ }^{\circ} \mathrm{F}$ & $19000-26600+$ \\
Heating Value, HHV, BTU/lb & $5490-13860$ \\
\hline
\end{tabular}

capture such inherent value in operating flexibility that SES' technologies provide.

\section{Phased Approach}

Feedstock characterization and testing campaigns fit well with and can accelerate a staged approach to project development. Each stage is an option that is a right but not an obligation to take action in the future. While commercial gasification technology platforms are well known to provide the option for carbon capture, SES' gasification technology adds additional value by providing optionality through fuel flexibility, as discussed above, and staging of project execution. SES is in the unique position to perform the following feedstock validation testing for its customers to provide an optimum plant design, plan for technical and commercial risk mitigation, and customer assurance on gasification performance for the chosen feedstocks. The four main tests are:

1) Feedstock properties evaluation;

2) Bench scale gasification;

3) Pilot scale gasification;

4) Commercial scale gasification.

As illustrated in Figure 6, each stage provides an opportunity for project viability assessment, and allows customers an off-ramp to project development spending if the project does not appear to be viable at that particular stage. Proving feedstock applicability in a commercial scale allows customers to accelerate the development of a project by removing or reducing feedstock and gasification technology risk. The proactive approach results in a higher net present value ("Active NPV") that shall exceed net present value from the passive approach to project development ("Passive NPV") due to higher risks associated with the latter.

SES has demonstrated this risk reducing-staged approach to project execution through its joint venture with Yima Coal Industry Group ("Yima”), which is SES' second project that is under construction in Henan Province, China. SES is a $25 \%$ owner of this joint venture. Following preliminary coal characterization and testing, SES leveraged its commercial testing capabilities at the ZZ Plant, which shifted from the plant's design coal (40 wt $\%$ ash bituminous coal washing by-product) to a subbituminous coal with $33-37 \mathrm{wt} \%$ ash that was provided by Yima. During the test, the plant achieved high carbon conversion rates and full load throughput. This test along with other coal testing campaigns provided a clear demonstration of the flexibility of SES' technology in gasifying many ranks of coal efficiently. Of equal importance is the fact that Yima owns and operates an entrained flow gasification plant and one of Asia's largest fixed bed gasification plants but selected SES' gasification process over these alternative gasification techno- 


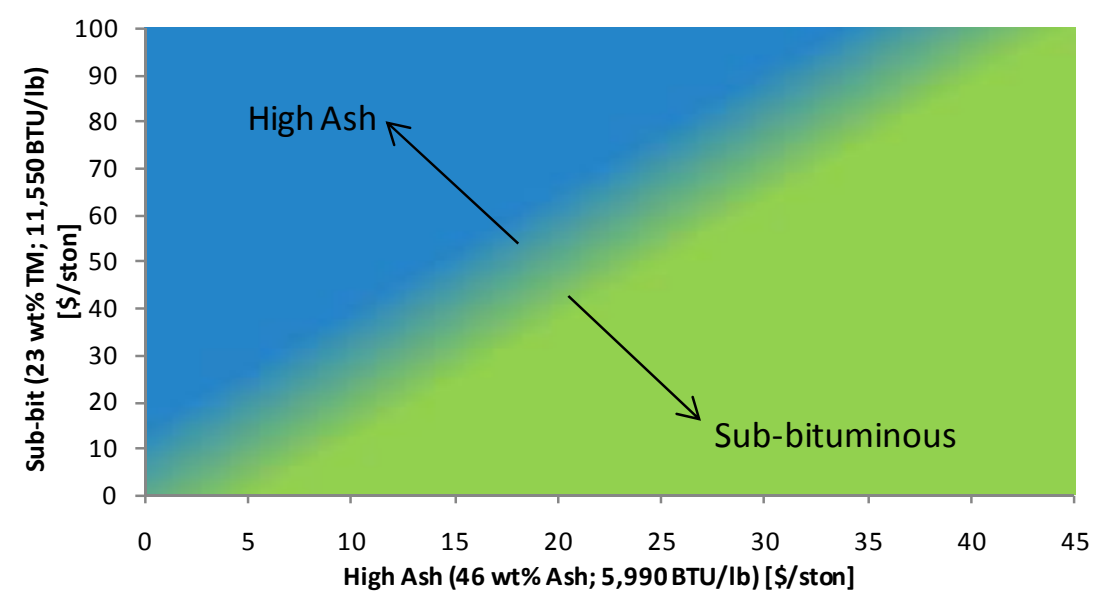

Figure 4. Example U-GAS fuel selection flexibility.

REDUCED UNCERTAINTY - INCREASING NET PRESENT VALUE (NPV)

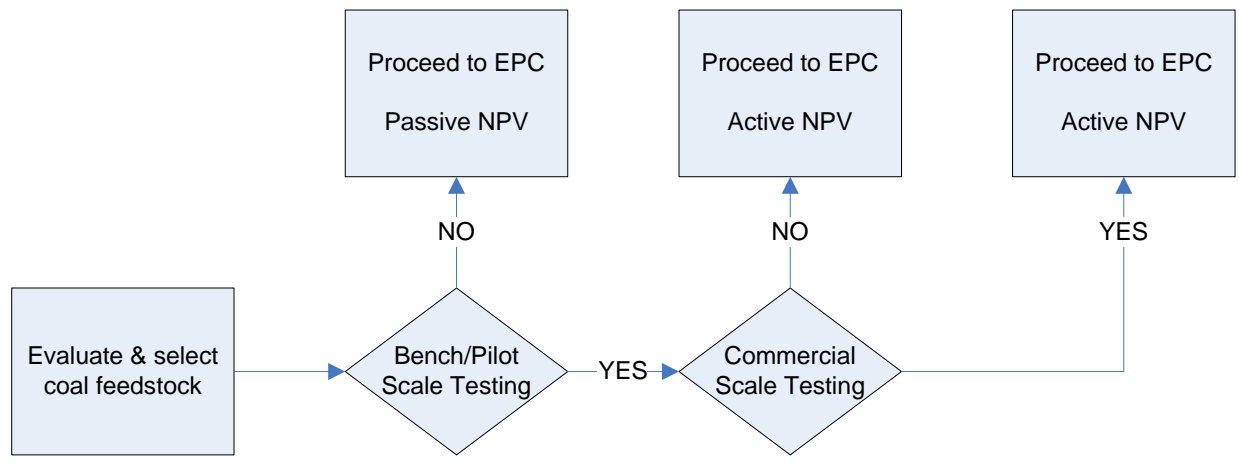

Figure 5. Options valuation through project staging.

logy platforms for Yima's new coal-to-chemical park.

SES' ZZ Plant continues to enable customers to meet their project needs through coal campaigns on feedstock imported by potential licensees for commercial scale testing. In December 2010, SES worked with Ambre Energy to test almost 3300 short tons of their Australian brown coal that had been shipped to the ZZ Plant from Queensland, Australia. This test again proved U-GAS efficiency and effectiveness on difficult feedstocks by reaching over $82 \%$ cold gas efficiency and greater than $98 \%$ carbon conversion. It's this platform of commercial scale feedstock gasification that enables SES' potential project partners and licensees to progress their projects with a commercial and bankable technology solution.

\section{Conclusion}

SES has made significant improvements to the design, operation, and efficiency of the U-GAS technology and the $\mathrm{ZZ}$ Plant. Included in these improvements is the FMS. Moreover, the ZZ Plant consistently demonstrates operating flexibility and greater than 98\% availability, 98\% carbon conversion, and 80\% cold gas efficiency. SES provides its customers with real options in the form of operating flexibility and phased project development. Both have been demonstrated by SES through existing operations at the ZZ Plant and the execution of SES' Yima joint venture project. Growing interest by third parties in SES' gasification solutions, including the successful commercial testing and feasibility study of Ambre Energy's high ash Queensland coal, is further testament to the advantages presented by SES

\section{REFERENCES}

[1] C. Higman and M. van der Burgt, "Gasification,” Gulf Professional Publishing, 2008.

[2] M. C. Woods, P. J. Capicotto, J. L. Haslbeck, N. J. Kuehn, M. Matuszewski, L. L. Pinkerton, et al., "Cost and Performance Baseline for Fossil Energy Plants DOE/NETL2007/1281," National Energy Technology Laboratory, 2007.

[3] L. M. Bartone and J. White, "Industrial Size Gasification for Syngas, Substitute Natural Gas and Power Production 
DOE/NETL-401/040607,” National Energy Technology Laboratory, 2007.

[4] A.-G. Collot, "Matching gasification technologies to coal properties,” International Journal of Coal Geology, 2006, pp. 191-212.

[5] B. Bryan, R. Laurens, A. Kramer, J. Hudziak, F. Lau,
T.-P. Chen, et al., "Flex-Fuel Test Facility: Evaluation of Fluidized-Bed Gasification for IGCC Power Production with High-Ash Indian Coal,” International Pittsburgh Coal Conference, 2005. 